\title{
Health and other impacts of community food production in Small Island Developing States: a systematic scoping review
}

\author{
Emily Haynes, ${ }^{1}$ Catherine R. Brown, ${ }^{2}$ Constance Wou, ${ }^{3}$ Chris Vogliano, ${ }^{4}$ Cornelia \\ Guell, ${ }^{1}$ and Nigel Unwin, ${ }^{3}$ on behalf of the Community Food and Health Project ${ }^{5}$
}

Suggested citation Haynes E, Brown CR, Wou C, Vogliano C, Guell C, Unwin N, the Community Food and Health Project. Health and other impacts of community food production in Small Island Developing States: a systematic scoping review. Rev Panam Salud Publica. 2018;42:e176. https://doi.org/10.26633/RPSP.2018.176

ABSTRACT Objective. To explore what is known on community-based food production initiatives (CFPIs) in Small Island Developing States, particularly the health, social, economic, and environmental impacts of and on CFPIs.

Methods. This was a systematic scoping review using 14 electronic databases to identify articles published from 1997 to 2016 on the topic of CFPIs in Small Island Developing States. From 8215 articles found, 153 were eligible and abstracted. Analysis focused on geographic location, typology, methodology, study design, theoretical frameworks, and impacts.

Results. Most research was conducted in the Pacific or Caribbean (49\% and $43 \%$ of studies, respectively) and primarily focused on fishing and crop farming $(40 \%, 34 \%)$. Findings indicate a predominance of research focusing on the environmental impact of marine and coastal resources on CFPIs, and very limited evidence of CFPI impact on human health, particularly nutrition and diet-related outcomes. There was a lack of explicit theoretical frameworks to explain the impacts of CFPIs.

Conclusions. Evidence of impacts of CPFIs in Small Island Developing States is limited and the approaches taken are inconsistent. This review demonstrates the need and provides a basis for developing a coherent body of methods to examine the impacts of CFPIs and provide evidence to guide policy, especially as it relates to health.

Keywords Food and nutrition security; food production; agricultural cultivation; animal husbandry; fishing industry; noncommunicable diseases; environment and public health; Pacific Islands; Caribbean region.

Small Island Developing States (SIDS) have some of the highest rates of noncom-

\footnotetext{
European Centre for Environment \& Human Health, University of Exeter Medical School, Truro, United Kingdom.

2 George Alleyne Chronic Disease Research Centre, The University of the West Indies, Bridgetown, Barbados. Send correspondence to Catherine Brown, catherine.brown@cavehill.uwi.edu

3 Medical Research Council Epidemiology Unit, University of Cambridge, Cambridge, United Kingdom.

4 School of Public Health, Massey University, Wellington, New Zealand.

See Acknowledgements for list of investigators.
}

municable diseases (NCDs) globally, particularly obesity, diabetes, and related NCDs $(1-3)$. Major determinants of the NCD burden in these countries include extensive changes to food systems, which are attributed to globalization and has led to a "nutrition transition" $(4-6)$. Across SIDS and low- and middle-income countries (LMICs) more widely, this transition is characterized by a dietary shift away from fruits, vegetables, and high-fiber staples, and towards energy-dense and highly processed foods. Related factors are poor agro-ecological conditions for agriculture; poor storage and transport leading to wasteful supply chains; export of local food products to other countries; reliance on food imports; and limited technology and know-how (7). Thus, many SIDS lack food sovereignty and are vulnerable to food insecurity. Increasing local food production, particularly of non- or minimallyprocessed foods, is seen as a pre-requisite to effective long-term NCD prevention. 
Community-based food production initiatives (CFPIs) is one approach to improving food and nutritional security and sovereignty $(7-9)$. For this study, CFPIs were defined as being locally owned and managed and producing fresh or minimally-processed foods for local consumption $(8-10)$. Previous reviews on the relationships between local food production and health have found limited evidence. Most studies have focused on maternal and child health; few have examined nutrition from the perspective of NCDs $(11-14)$. Additionally, the majority of research has focused on Sub-Saharan Africa and South Asia (12). Given the heightened vulnerability of SIDS, they are a key location for assessing CFPIs.

This study is nested within a larger project aiming to develop a theoretical framework and methods for evaluating the impact of CFPIs on risk factors for NCDs, social and economic well-being, and the environment (15). This systematic scoping review was undertaken as a first step. The inclusive and comprehensive nature of scoping reviews facilitates the inclusion of a range of study designs; this is particularly useful when applied to underexplored or heterogeneous topics such as this to inform further research, practice, and policy $(16-18)$.

The aim of this systematic scoping review was to identify studies that report the health, social, economic, and environmental impacts of CFPIs in SIDS, and to explore what is known about those CFPIs, including their number, distribution, and characteristics. Specific objectives were to: (i) identify the study designs and data collection methods used to investigate the health, social, economic, and environmental impacts of CFPIs; (ii) construct a typology of these CFPIs; (iii) identify theoretical causal frameworks for impacts of these CFPIs; and (iv) identify the health, social, economic, and environmental impacts on CFPIs.

\section{MATERIALS AND METHODS}

\section{Methodological framework}

Scoping reviews are used to map the concepts underlying a research area and the main sources and types of evidence available (19). They are increasingly used in the health and social sciences. However, to address criticism that their methodological approaches and reporting are inconsistent, a more systematic and transparent approach has been proposed $(20-23)$ and an extension to the Preferred Reporting Items for Systematic Reviews and Meta-Analysis (PRISMA) for scoping reviews is being prepared (24). The present study followed this systematic approach, including reporting of findings according to general PRISMA guidance, when appropriate.

In keeping with scoping review methodology, the protocol was developed iteratively and informed by the results of initial literature searches and consultation with the wider project team. The full protocol has been published by University of Cambridge's Medical Research Council Epidemiology Unit (15).

\section{Definitions of key terms}

Owing to the absence of a universallyrecognized definition and to the breadth of the research question, an iterative approach was applied to defining CFPIs. The NOVA classification was applied to define fresh and minimally-processed foods (25):

- Community food production initiative: owned, organized, and managed locally, and producing either fresh or minimally-processed food for local consumption.

- Fresh food: 'unprocessed' or 'natural' edible parts of plants (seeds, fruits, leaves, stems, roots) or animals (muscle, offal, eggs, milk), as well as fungi, algae, and water, after separation from nature (25).

- Minimally-processed food: natural foods altered only by processes such as removal of inedible or unwanted parts, drying, crushing, grinding, fractioning, filtering, roasting, boiling, pasteurization, refrigeration, freezing, placing in containers, vacuum packaging, or non-alcoholic fermentation, without the addition of substances to the original food (25).

- Locally owned and managed initiatives: food production owned and managed within that SIDS.

- Food produced for local consumption: food produced for consumption within that SIDS.

\section{Identifying studies}

A systematic and extensive search was conducted on $2-4$ August 2017 in the following databases: MEDLINE $^{\circledR}$
(U.S. National Library of Medicine, Bethesda, Maryland, United States), Excerpta Medica Database (Elsevier, Amsterdam, Netherlands); Cumulative Index of Nursing and Allied Health Literature (EBSCO Publishing, Ipswich, Massachusetts, United States); Scopus (Elsevier, Amsterdam, Netherlands); Conference Proceedings Citation Index (Clarivate Analytics, Philadelphia, Pennsylvania, United States); Social Science Citation Index - Social Science and Humanities (Clarivate Analytics, Philadelphia, Pennsylvania, United States) Arts \& Humanities Citation Index (Clarivate Analytics, Philadelphia, Pennsylvania, United States); Emerging Sources Citation Index (Clarivate Analytics, Philadelphia, Pennsylvania, United States); Applied Social Sciences Index and Abstracts (ProQuest, Ann Arbor, Michigan, United States); Econlit (American Economic Association, Nashville, Tennessee, United States); Agricultural Online Access (United States National Agriculture Library, Beltsville, Maryland, United States); The International System for Agricultural Science and Technology (Food and Agriculture Organization of the United Nations, Rome, Italy); Western Pacific Region Index Medicus (World Health Organization Western Pacific Regional Office, Manila, Philippines); and Latin American and Caribbean System on Health Sciences Information (Pan American Health Organization/ World Health Organization, São Paulo, Brazil). Database selection was informed by the systematic review protocol of Durao and colleagues (12) on food security in LMICs and was intended to cover major sources of health, social, economic, environmental, and agricultural sciences.

The search was not restricted by language, but it did exclude articles published before January 1997 and after December 2016. The SIDS included were those listed by the United Nations, with the addition of Tokelau (26). Search terms are listed in the review protocol (15).

\section{Study selection}

Identified citations were downloaded into an online bibliographic database, Rayyan (Qatar Computing Research Institute, Data Analytics, Doha, Qatar; 27). Title and abstracts were screened independently in duplicate $(\mathrm{EH}, \mathrm{CB})$. Articles were considered eligible for inclusion if they met three criteria: (i) concern at least 1 of the 58 SIDS countries/territories; (ii) report on CFPIs (as previously defined); 
and (iii) report on health, social, economic, or environmental impacts of/on CFPIs. When information was insufficient, an inclusive approach was taken by including the citation for full-text review. Conflicts were resolved by discussion with a third reviewer (CG).

\section{Data charting}

Full-text screening followed a step-wise approach (Figure 1). Each record was examined chronologically as follows: (i) Does it involve food production in a SIDS?; (ii) Is the food production managed/owned locally?; (iii) Is the food produced predominantly for local consumption?; and (iv) Does it discuss impacts of/on the CFPI? Only articles that were affirmative ("yes") for all four screening questions were included; those for which the answer was "unsure" were excluded.

Full-text screening and data abstraction were performed by four independent reviewers (CB, CW, $\mathrm{EH}, \mathrm{NU}) ; 10 \%$ of randomly-selected articles were checked by a fifth reviewer $(\mathrm{CV})$ to test the reliability of data abstraction. Inconsistencies were resolved by group discussion.

A data abstraction form was iteratively developed in REDCap ${ }^{\odot} 7.3 .4$ (Vanderbilt University, Nashville, Tennessee, United States), a secure online data collection platform (16). Records that reported the impacts of CFPIs (Objective A) were ab- stracted into that form; while records that reported the impacts on CFPIs (Objective D) were abstracted using a simple data abstraction form developed in Microsoft Excel ${ }^{\mathrm{TM}}$ (Microsoft Corp., Redmond, Washington, United States).

\section{Data synthesis}

Impacts of CFPIs, impacts on CFPIs, and measured outcomes of impacts on CFPIs were organized into a coding framework to assist with analysis (available from the corresponding author upon request). Findings are reported as a qualitative narrative, with quantities tallied where appropriate. As is the case for scoping reviews, study quality was not assessed nor were meta-analyses performed (23).

\section{RESULTS}

Of 8215 records identified, 153 studies (S1-S153) met the eligibility criteria and were included in the review (Figure 1). The complete bibliographic list of these articles (S1 - S153) is available as Annex 1.

Studies focused on 42 of the 58 SIDS countries and territories. Despite this wide geographic range, 23 of the SIDS contributed only 3 or fewer studies to this review. Most of the research was conducted in the Pacific ( $n=75$ studies; $49 \%$ ) and Caribbean regions $(n=66 ; 43 \%)$, pre-

\section{FIGURE 1. Flowchart of the literature search and screening}

\begin{tabular}{|c|c|}
\hline $\begin{array}{l}\text { Articles identified through database } \\
\text { searching } \\
(n=8215)\end{array}$ & \multirow[b]{2}{*}{ Duplicate articles excluded ( $n=1811)$} \\
\hline & \\
\hline $\begin{array}{l}\text { Articles after duplicates removed } \\
\qquad(n=6404)\end{array}$ & \\
\hline & Articles excluded ( $n=5875)$ \\
\hline $\begin{array}{l}\text { Articles eligible after title and } \\
\text { abstract screening } \\
\qquad(n=529) \\
\text { (Impact of CFPI }=274 ; \\
\text { Impacts on CFPI }=255)\end{array}$ & $\begin{array}{l}\text { Inaccessible articles }(n=31) \\
\text { (Impacts of CFPI }=17 \text {; Impacts on CFPI }=14) \\
\text { Articles excluded }(n=345)\end{array}$ \\
\hline & (Impacts of CFPI = 186; Impacts on CFPI = 159) \\
\hline$\nabla$ & - Not food production or in SIDS $(n=141)$ \\
\hline $\begin{array}{l}\text { Articles eligible after full-text } \\
\text { screening } \\
\qquad(n=153) \\
(\text { Impacts of CFPI }=71 ; \\
\text { Impacts on CFPI }=82)\end{array}$ & $\begin{array}{l}\text { - Initiative not owned/managed locally }(n=58) \\
\text { - Food not for local consumption }(n=58) \\
\text { - Not research on impacts of/on CFPI }(n=77) \\
\text { - Not research on impacts relevant to the review }(n=6) \\
\text { - Manual duplicate }(n=5)\end{array}$ \\
\hline
\end{tabular}

Source: Prepared by the authors, using study data.

Note: CFPI - community food production initiative; SIDS - small island developing state. dominantly Papa New Guinea $(n=16)$, Solomon Islands $(n=16)$, and Cuba $(n=$ 15). A range of study designs were employed to evaluate the impacts of/on CFPIs, and the majority reported the results of primary research $(n=125 ; 82 \%)$ derived from a cross-sectional design $(n=$ $88 ; 58 \%)$. Primary research studies commonly applied quantitative $(n=60 ; 48 \%)$ and mixed methods $(n=42 ; 34 \%)$ approaches; qualitative approaches (alone) were employed in 23 studies (18\%; Figure 2).

\section{Types of CFPIs}

Most studies reported evaluations of current practices, rather than novel initiatives or programs. Five major types of CFPIs were identified: marine and coastal resources, farming (including crop and livestock subgroups), gardens, urban agriculture, and food systems. CFPIs classified as marine and coastal resources included food production techniques such as fishing, coastal foraging, and aquaculture. These initiatives mainly concerned smallscale, subsistence or artisanal fishing, and included initiatives such as villagerun fishing cooperatives (S88) and community-based resource monitoring and provisioning services (S3). Garden initiatives included community, home, and school gardens. Urban agriculture initiatives were reported in highly urbanized areas of Cuba and Singapore. One of the CFPIs classified as food systems reported on wider policy initiatives to alter food environments, such as increasing public market size and reducing barriers to roadside vending of local produce in Fiji and Tonga (S126). While there is a clear emphasis on fishing in the Pacific and farming in the Caribbean (Table 1), the range of their impacts (health/social/ economic/environmental) was otherwise well distributed in both regions.

\section{Impacts of CFPIs}

Most studies examining impacts of CFPIs focused on the environmental impact $(n=47)$; their social impact $(n=23)$ was the least examined (Table 2). Studies that evaluated the impacts of CFPIs on human health were of particular interest to this review; 35 such studies were identified. These were predominantly quantitative or mixed-methods studies of marine and coastal resources $(n=11)$ or farming $(n=15)$, with few reporting garden initia- 
FIGURE 2. Distribution and interlinkage of impacts of and on community food production initiatives (CFPIs), as described by the included studies conducted in SIDS in 1997-2016

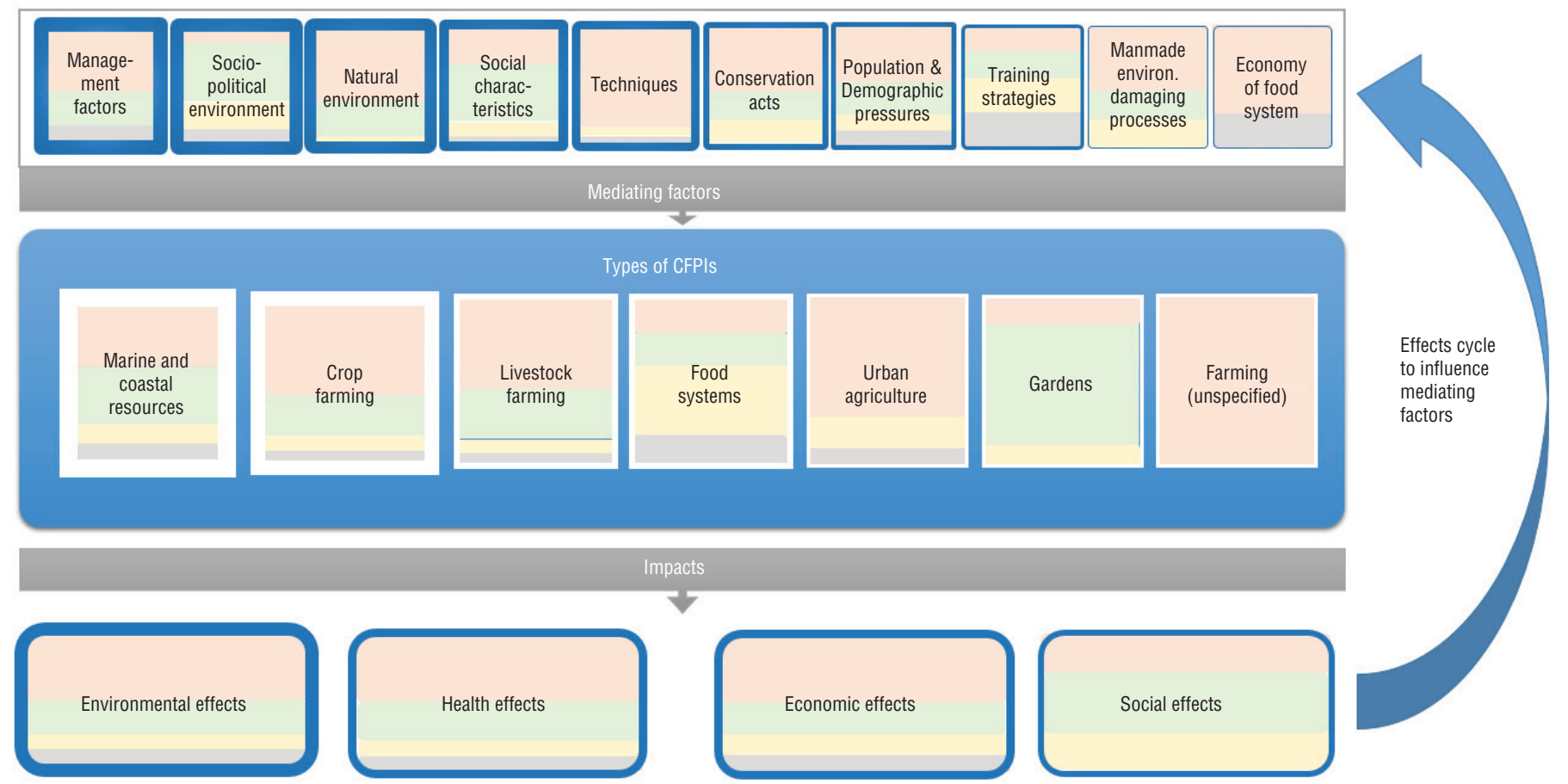

Source: Prepared by the authors, using study data.

Note: Box border width indicates proportion of included studies. $\quad$ indicates quantitative; _ indicates mixed method; indicates qualitative; $\quad$ indicates other.

TABLE 1. Matrix of studies conducted in SIDS in 1997-2016, by type of community food production initiative (CFPI) and by region

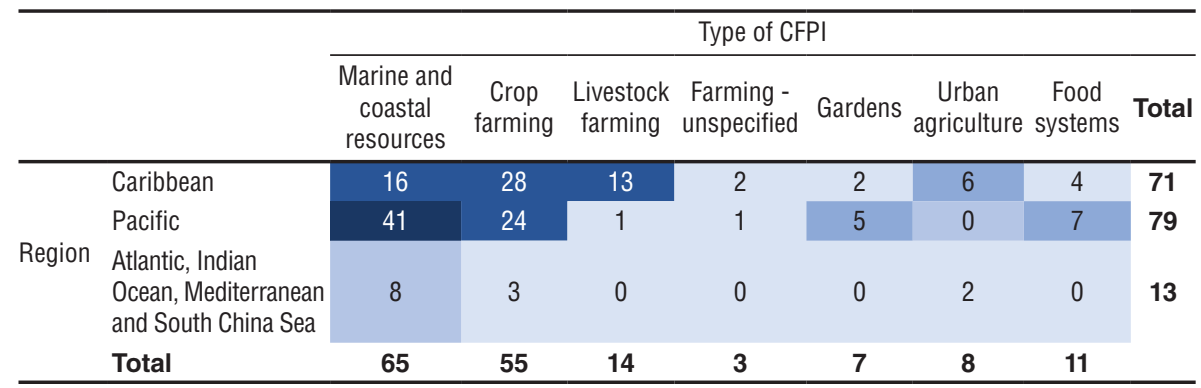

Source: Prepared by the authors, using study data.

Note: Numbers denote number of studies, with overlap between types of community food production initiatives where necessary. The darker the blue, the higher number of studies.

tives $(n=5)$ or urban agriculture $(n=4)$. Health impacts coded, in order of frequency, were: agricultural production/ catch/yield, dietary consumption, pollutants (water/air/soil contamination; pesticides), nutritional composition (nutritional value/mineral content), anthropometric (e.g., weight, body fat), biomedical (e.g., blood glucose, triglycerides), medicinal, psychological/well-being, communicable illnesses, and noncommunicable diseases.

Of these 35 studies reporting the human health impacts of CFPIs, only 7 implemented and evaluated a community food production intervention/program (most in the Pacific). These applied quantitative $(n=3)$ and mixed-methods $(n=$ 4) approaches to interventional study design and evaluated health-related impacts of gardens $(n=3)$, crop farming $(n=3)$, and marine and coastal resources $(n=1)$. Data collection instruments included 7-day food frequency questionnaires and 24-hour recall to report health impacts evaluated as dietary outcome measures, namely dietary intake and nutritional composition of the diet (S61, S76, S111, S148). Biomedical and anthropometric measures were reported as health-related outcomes by 1 study (S76), specifically body mass index, waist circumference, blood pressure, and blood glucose. Three of the interventional studies reported productivity as an outcome, particularly the contribution to subsistence and food security in the Solomon Islands, Papa New Guinea, and Trinidad and Tobago (S66, S119, S128).

The remaining 27 non-interventional studies that reported human health impacts evaluated the following measures: dietary intake (S41, S63, S71, S87); anthropometric measures (S77, S95); communicable disease, predominantly related to pollutants (S13, S86, S135); and mental health and wellbeing (S41, S108). Two articles reported increases in heart disease, hypertension, diabetes, obesity, and cancers following a nutrition transition from local food consumption towards imported foods (S34, S134). However, a large proportion of these studies $(n=13 ; 38 \%)$ reported the health impact of CFPIs as increased agricultural productivity, and thus, improved food security (S3, S20, S58, S80, S82, S88, S97, S98, S130, S132 - 134).

Environmental impacts of CFPIs were the most commonly reported type of impact. Environmental impacts coded, in order of frequency, were: conservation/ sustainability (including biocapacity), 
TABLE 2. Matrix of studies conducted in SIDS in 1997-2016 examining impacts of and on community food production initiatives (CFPIs)

\begin{tabular}{|c|c|c|c|c|c|c|c|c|c|}
\hline & & \multicolumn{8}{|c|}{ Type of CFPI } \\
\hline & & $\begin{array}{c}\text { Marine and } \\
\text { coastal resources }\end{array}$ & Crop farming & $\begin{array}{l}\text { Livestock } \\
\text { farming }\end{array}$ & $\begin{array}{l}\text { Farming - } \\
\text { unspecified }\end{array}$ & Gardens & $\begin{array}{c}\text { Urban } \\
\text { agriculture }\end{array}$ & $\begin{array}{c}\text { Food } \\
\text { systems }\end{array}$ & Total \\
\hline \multirow[t]{4}{*}{ Impact of CPFI } & Health & 11 & 12 & 3 & 1 & 5 & 2 & 1 & 35 \\
\hline & Economic & 15 & 9 & 1 & 0 & 2 & 3 & 1 & 31 \\
\hline & Environment & 24 & 13 & 3 & 1 & 2 & 3 & 1 & 47 \\
\hline & Total impacts of CFPls & 59 & 39 & 10 & 3 & 13 & 8 & 4 & \\
\hline \multirow{9}{*}{ Impact on CFPI } & Management factors (lower level) & 10 & 9 & 0 & 0 & 0 & 1 & 1 & 20 \\
\hline & Training/strategies & 1 & 3 & 0 & 0 & 1 & 0 & 2 & 6 \\
\hline & Conservation acts & 8 & 0 & 0 & 0 & 0 & 0 & 0 & 8 \\
\hline & Social characteristics & 7 & 4 & 0 & 0 & 0 & 0 & 4 & 13 \\
\hline & Population/demographic pressures & 2 & 4 & 0 & 0 & 0 & 0 & 2 & 7 \\
\hline & Economy of food system (individual level) & 1 & 1 & 0 & 0 & 0 & 0 & 1 & 3 \\
\hline & Other & 0 & 1 & 1 & 0 & 0 & 0 & 0 & 2 \\
\hline & Total impacts on CFPI & 45 & 37 & 7 & 0 & 1 & 4 & 16 & \\
\hline & Total & 104 & 76 & 17 & 3 & 14 & 12 & 20 & \\
\hline
\end{tabular}

Source: Prepared by the authors, using study data.

Note: Numbers denote number of studies, with overlap between types of community food production initiatives where necessary. The darker the green, the higher number of studies.

agricultural production/catch/yield, pollutants (e.g., water/air/soil contamination; pesticides), soil quality, $\mathrm{CO}_{2}$ savings, energy efficiency, and climate change. In particular, the environmental impact of fishing was predominantly explored ( $n=25 ; 43 \%$ of those regarding marine and coastal resources). Existing catch data from fisheries was commonly utilized to determine conservation-related environmental impacts of fishing practices, and in these cases, official data reports were compared to evidence derived from the grey literature and local expert knowledge (S153). Spatial analysis of land use was used to explore impacts on water quality (S140). Interviews and field observations were also used to explore environmental impacts or stakeholder perceptions of such (S25, S26, S41, S49).

Social and economic impacts were assessed largely through interviews, focus groups and a variety of cross-sectional surveys. Specific to social impacts, studies largely employed ethnographic approaches (S52, S61, S67, S88, S121, S123) and one study drew upon visual techniques, i.e., mapping, participatory photography, and photo elicitation (S93). Social impacts coded, in order of frequency, were: knowledge, satisfaction/enjoyment (life or job), social participation/interaction, reliance and resilience (self or community), living conditions/dynamics, gender roles, values (social/cultural, equity, identity), relationships, attitudes (acceptability, empowerment), poverty, and change (infrastructure). Economic impacts coded, in order of frequency, were: income/subsistence (e.g., sales, revenue, importance to income), agricultural production/catch/yield, expenditure/cost, profitability, technological innovation, and economic resilience.

Given their wide reach, studies that reported agricultural production/catch/ yield impacts and pollutants were categorized as multiple impact types depending on the specifics of each study.

\section{Impacts on CFPIs}

The reports of studies concerning impacts on various types of CFPIs (Table 3 ) also reflected the predominance of research on marine and coastal resources and farming. The most commonly explored impacts were management factors $(n=20 ; 20 \%)$ and socio-political environment $(n=16 ; 16 \%)$. The impacts of conservation acts, such as Marine Protected Areas and community provision interventions on fishing, were also frequently reported.

Measured outcomes of the impacts on CFPIs indicate the inherently cyclic nature of impacts and outcomes (Table 3). Food security was the most frequently reported outcome among these studies ( $n=108 ; 60 \%$ ), and not surprisingly, given the inclusion criteria for this review, food production specifically was most widely reported as an indicator of food security. Among other outcomes, conservation and sustainability were highly reported, as were those related to social and economic environments. There is a clear cyclic interlinkage between the impacts of different types of CFPIs and the factors that impact on them (Figure 2).

\section{Theoretical frameworks}

There was a general paucity of explicit theoretical frameworks or logic models reported by authors to explain how CFPIs might bring about health, social, economic, or environmental change. Since this systematic scoping review was particularly interested in frameworks and models that might explain underlying mechanisms or causal relationships 
TABLE 3. Matrix of studies conducted in SIDS in 1997-2016 examining impacts on community food production initiatives (CFPI), by measured outcomes

\begin{tabular}{|c|c|c|c|c|c|c|c|c|c|c|c|c|}
\hline & & \multicolumn{11}{|c|}{ Mediating factor } \\
\hline & & $\begin{array}{c}\text { Socio- } \\
\text { political } \\
\text { environment } \\
\text { (higher level) }\end{array}$ & $\begin{array}{l}\text { Management } \\
\text { factors } \\
\text { (lower level) }\end{array}$ & $\begin{array}{l}\text { Training/ } \\
\text { strategies }\end{array}$ & $\begin{array}{l}\text { Conservation } \\
\text { acts }\end{array}$ & $\begin{array}{c}\text { Social } \\
\text { characteristics }\end{array}$ & $\begin{array}{l}\text { Population/ } \\
\text { demographic } \\
\text { pressures }\end{array}$ & $\begin{array}{c}\text { Economy of } \\
\text { food system } \\
\text { (individual } \\
\text { level) }\end{array}$ & $\begin{array}{c}\text { Natural } \\
\text { environment }\end{array}$ & $\begin{array}{c}\text { Man-made } \\
\text { environmentally- } \\
\text { damaging } \\
\text { processes }\end{array}$ & Techniques & Total \\
\hline \multirow{8}{*}{$\begin{array}{l}\text { Impact } \\
\text { outcome } \\
\text { measured }\end{array}$} & $\begin{array}{l}\text { Food security } \\
\text { (unspecified) }\end{array}$ & 3 & 3 & 1 & 0 & 3 & 2 & 1 & 2 & 0 & 1 & 16 \\
\hline & $\begin{array}{l}\text { Food } \\
\text { production }\end{array}$ & 4 & 7 & 1 & 3 & 4 & 3 & 1 & 4 & 1 & 6 & 34 \\
\hline & Food access & 3 & 3 & 1 & 2 & 4 & 2 & 1 & 1 & 1 & 1 & 19 \\
\hline & $\begin{array}{l}\text { Subsistence/ } \\
\text { resilience }\end{array}$ & 2 & 1 & 2 & 0 & 2 & 2 & 1 & 1 & 0 & 1 & 12 \\
\hline & $\begin{array}{l}\text { Food } \\
\text { consumption }\end{array}$ & 2 & 1 & 1 & 0 & 2 & 1 & 1 & 0 & 0 & 0 & 8 \\
\hline & Practice & 4 & 2 & 3 & 2 & 3 & 2 & 1 & 2 & 0 & 1 & 20 \\
\hline & $\begin{array}{l}\text { Risk } \\
\text { prevention }\end{array}$ & 0 & 0 & 0 & 0 & 0 & 0 & 0 & 0 & 0 & 3 & 3 \\
\hline & Total & 33 & 33 & 15 & 11 & 28 & 18 & 7 & 16 & 4 & 15 & \\
\hline
\end{tabular}

Source: Prepared by the authors, using study data.

Note: Numbers denote number of studies, with overlap between types of community food production initiatives where necessary. The darker the green, the higher number of studies.

between CFPIs and impacts, descriptive explanations were extracted from these studies. Implicit theories of change were more widely explored for social impacts than other types of impacts. Assumed relationships between CFPIs and social impacts included their facilitation of community resilience, knowledge, cooperation, and participation (S23, S77, S149). The social benefit of local food production was attributed to women's participation in farming in Timor-Leste (S26) and to household subsistence in Comoros (S67). Garcia-Quijano and colleagues (S52) theorized that the satisfaction and enjoyment experienced through food production promote values of independence and family time in Puerto Rico, which are perhaps more important in SIDS communities than earning a substantial, steady salary. One study attributed Fijian fisheries' poor financial returns to narrow management style, in particular an "imposition of business practices and perceptions on how it ought to function [solely] as a profit maximizing venture" (S88). Although few studies reported health impacts of CFPIs, increased physical activity and a dietary shift away from imported processed foods to local produce were theorized to bring about health benefits associated with local agriculture in Samoa (S77).

\section{DISCUSSION}

This systematic scoping review maps out what is known on CFPIs in SIDS, i.e., their number, distribution, characteristics, and impacts on health, social and economic well-being, and the environment, as well as the impacts affecting CFPIs themselves. Though the distribution of research across SIDS is uneven, the publication span of $72 \%$ of the 58 countries/ territories is indicative of a growing interest in and recognition of the importance of these types of initiatives for food security; health, social, and economic well-being; and the environment in SIDS.

A predominance of the research focused on marine and coastal resources in the Pacific and crop farming in the Caribbean, evaluating the environmental impacts of both. Generally, there was an even distribution across the four impact domains (Table 2). However, only 7 of the 35 studies that examined health impacts evaluated the implementation of targeted food production programs on humans. Of studies reporting impacts on CFPIs, the most commonly reported mediating factors (management factors, socio-political environment, and natural environment) and outcomes (food production and conservation/sustain- ability) reflect a relatively wide scope and an intertwining of environmental and climate change issues with food security and policy (Figure 2).

These key findings indicate a number of gaps in the literature. It is not surprising that a high proportion of these studies were focused on fishing activities-a readily available and priority resource in SIDS. However, this predominance might simply reflect greater research into environmental issues, such as marine conservation, fishing stocks, and coastal reef health, than food production in these countries, with the latter simply encompassed within these environmental studies. Regardless, this predominance illustrates a focus on climate change, resource capacity, and sustainability within a food security landscape, which have been emphasized before in $\operatorname{SIDS}(28,29)$.

We also found that that the impacts of and on local food production are largely reported in the context of environmental issues. Recognizing not only the interlinkage, but also the cyclical associations between the environmental impacts on food production, and the health, social, economic, and environmental outcomes of CFPIs that are impacted is crucial and integral to informing future initiatives. 
A food systems approach is integral to facilitating interdisciplinary action to improve food security (28). Thus, the dearth of evidence regarding nutritionrelated health impacts of CFPIs and of changing local food systems in SIDS to enhance local consumption is important to note. In the wider context of LMICs, household agricultural strategies have increased micronutrient intake among women and children (30); however, there is limited evidence of their subsequent impact on micronutrient status, NCDs, or the impact of whole community initiatives on the total, local population (30). Therefore, it seems likely that the research gap regarding nutrition-related health impacts of local food production is not unique to SIDS, but exists in the wider context of LMICs (12), and possibly in high-income countries as well (31). The findings of ongoing systematic reviews should provide valuable insights into the impact of community food interventions on food security in LMICs and high-income countries $(12,31)$. In the context of SIDS, our further research following this review aims to respond to this gap by providing evidence around local dietary patterns, food sourcing, and food insecurity in two SIDS settings, in an effort to develop evaluation tools for CFPIs in other settings (15).

While identifying the distribution and gaps in research, our typology of initiatives demonstrates alternative opportunities for community food production, such as under-researched gardens and urban agriculture (Table 2). This raises questions as to whether countries are taking advantage of these to boost local food production. It also challenges those that plan to use robust (experimental or quasi-experimental) study designs to evaluate the health impacts of CFPIs.

Limitations. This review illustrates an original, systematic, and interdisciplinary approach to examining the breadth of literature around impacts of and on CFPIs in SIDS. However, common to scoping reviews $(21,23)$, the iterative approach and breadth of the topic gave rise to various interpretations of what was "relevant" in the context of this research. This was further impacted by the lack of universal definitions for key terms and limited detail provided by authors. The ambiguity led to discrepancies in coding between the reviewers, which were resolved during frequent moderation, but had implications on the time taken to complete the review. The lack of theoretical frameworks reported for the impacts of CFPIs limited discussion on the third objective of this review. This is likely due to the varied disciplines of the included records, together with the understanding that most health interventions are not based on standardized theory, and those that are theory-based, apply only parts of the underlying theory (32). Finally, while our search methods aimed to identify published papers and reports, it is possible that other relevant initiatives were not published or that the search terms failed to identify them.

\section{Conclusions}

This systematic scoping review maps the evidence on CFPIs to support improved nutrition, prevent NCDs, and bring about other social, economic, and environmental benefits in SIDS populations. Seven types of CFPIs were identified in this review and a range of mixed methodologies were reported, varying based on type of impact reported. Primary evidence of nutrition and NCD-related health impacts of CFPIs is limited, but there is a predominance of research into environmental impacts. Regardless of impact, causal frameworks were rarely cited.

An interdisciplinary approach to research, maintaining a cyclic interrelation between food production and its wider environmental, economic, and social influences, is important to addressing two major global health topics: NCDs and climate change. As research in this area grows, there is an opportunity to develop coherent methodological approaches for monitoring and evaluating CFPIs and their associated impacts. Such approaches should be under-pinned by sound causal frameworks that are tested and refined as new evidence accrues.
Author contributions. $\mathrm{EH}$ and $\mathrm{CRB}$ contributed to data extraction, evidence mapping, wrote the first draft, and editing. CW and CV contributed to data extraction, evidence mapping, and editing. NU conceived the original idea; NU and CG contributed to the study design, data extraction, evidence mapping, and editing. All authors approved the final version.

Acknowledgements. In addition to the listed authors, the following investigators on the Community Food and Health Project $(\mathrm{CFaH})$ contributed to the development of the protocol for this scoping review: T. Alafia Samuels and Ian Hambleton (George Alleyne Chronic Disease Research Centre, Bridgetown, Barbados); Neela Badrie (The University of the West Indies, St. Augustine, Trinidad); Morgan Wairu and Viliamu Iese (University of the South Pacific, Suva, Fiji); Connie Donato-Hunt (Pacific Community, Noumea, New Caledonia); Florian Kroll (University of Witwatersrand, Johannesburg, South Africa); Rachel Nugent (Research Triangle International, Durham, North Carolina, United States); Nita G. Forouhi (MRC Epidemiology Unit, University of Cambridge, Cambridge, England) and Sara Benjamin-Neelon (John Hopkins Bloomberg School of Public Health, Baltimore, Maryland, United States).

\section{Conflict of interests: None declared.}

Funding. The project is supported by a Foundation Award from the Global Challenges Research Fund (Wiltshire, England), through the United Kingdom Medical Research Council (Cambridge, England); Grant No. MR/P025250/1). NGF acknowledges core Medical Research Council support (MC_UU_ $12015 / 5)$. The funders had no role in the study design, data collection or analysis, decision to publish, or preparation of the manuscript.

Disclaimer. Authors hold sole responsibility for the views expressed in the manuscript, which may not necessarily reflect the opinion or policy of the RPSP/ PAJPH and/or PAHO. 


\section{REFERENCES}

1. Global Burden of Disease Study collaborators. Global, regional, and national age sex specific all cause and cause-specific mortality for 240 causes of death, 1990-2013: a systematic analysis for the Global Burden of Disease Study 2013. Lancet. 2013; 385(9963):117-71.

2. Ng M, Fleming T, Robinson M, Thomson B, Graetz N, Margono C, et al. Global, regional, and national prevalence of overweight and obesity in children and adults during 1980-2013: a systematic analysis for the Global Burden of Disease Study 2013. Lancet. 2014;384(9945):766-81.

3. International Diabetes Federation. Diabetes atlas. $7^{\text {th }}$ ed. Brussels: IDF; 2015.

4. Popkin BM, Adair LS, Ng SW. Now and then: the global nutrition transition: the pandemic of obesity in developing countries. Nutri Rev. 2012;70(1):3-21.

5. World Health Organization. Global status report on noncommunicable diseases 2010: description of the global burden of NCDs, their risk factors and determinants. Geneva: WHO; 2011. Available from: http: / / www.who.int/nmh/publications/ncd_report2010/en/ Accessed 15 October 2017.

6. Swinburn BA, Sacks G, Hall KD, McPherson K, Finegood DT, Moodie ML, et al. The global obesity pandemic: shaped by global drivers and local environments. Lancet. 2011;378(9793):804-14.

7. International Food Policy Research Institute. Global nutrition report 2015: actions and accountability to advance nutrition and sustainable development. Washington DC: IFPR Institute; 2015. Available from: http:/ / www.ifpri.org/publication/global-nutrition-report-2015 Accessed 15 October 2017.

8. Trujillo AG. The hefty challenges of food sovereignty's adulthood: Synthesis paper. Canadian Food Studies. 2015;2(2):183-92.

9. United Nations System Standing Committee on Nutrition. Investments for healthy food systems: a framework analysis and review of evidence on food system investments for improving nutrition. Rome: UN; 2016. Available from: https://www.unscn.org/ uploads/web/news/document/EN-final-Investments-for-Healthy-Food-Systems-UNSCN.pdf Accessed 15 October 2017.

10. Food and Agricultural Organization. Growing greener cities in Latin America and the Caribbean: an FAO report on urban and peri-urban agriculture in the region. Rome: FOA; 2014. Available from: http://www.fao.org/3/a-i3696e.pdf Accessed 15 October 2017.

11. Tarasuk V. A critical examination of community-based responses to household food insecurity in Canada. Health Educ Behav. 2001;28(4):487-99.

12. Durao S, Schoonees A, Ramokolo V, Oliveira JMD, Kristjansson E. Communitylevel interventions for improving access to food in low- and middle-income countries. Cochrane Database of Systematic Reviews. Available from: http://www.cochrane. org/CD011504/PUBHLTH_community -level-interventions-for-improving-access-to-food-in-low-and-middle-incomecountries Accessed 15 October 2017.

13. Waage J, Hawkes C, Turner R. Current and planned research on agriculture for improved nutrition: a mapping and a gap analysis. A report for DFID. 21 August 2012. London: Leverhulme Centre for Integrative Research on Agriculture and Health; 2012.

14. Turner R, Hawkes C, Jeff W, Ferguson E, Haseen F, Homans H, et al. Agriculture for improved nutrition: the current research landscape. Food Nutri Bull. 2013; 34(4):369-77.

15. Community Food Production and Health $(\mathrm{CFaH})$ Collaborators. Community food production and health. Available from: http: / / www.mrc-epid.cam.ac.uk/research/global-public-health/communityfood-production-health/2018 Accessed 18 January 2018.

16. Mays N, Roberts E, Popay J. Synthesizing research evidence in studying the organisation and delivery of health services: research methods. N Fulop PA, A Clarke, N Black, eds. London: Routledge: 2001.

17. Arksey H, O'Malley L. Scoping studies: towards a methodological framework. Int J Soc Res Method. 2005;8(1):19-32.

18. Pham MT, Rajic A, Greig JD, Sargeant JM, Papadopoulos A, McEwen SA. A scoping review of scoping reviews: advancing the approach and enhancing the consistency. Res Synth Methods. 2014;5(4):371-85.

19. Arksey H, O'Malley L. Scoping studies: towards a methodological framework. Int J Soc Res Methodol. 2005;8(1):19-32.

20. Peters MD, Godfrey CM, Khalil H, McInerney P, Parker D, Soares CB. Guidance for conducting systematic scoping reviews. Int J Evid Based Health. 2015;13(3):141-6.

21. Colquhoun HL, Levac D, O'Brien KK, Straus S, Tricco AC, Perrier L et al., Scoping reviews: time for clarity in definition, methods, and reporting. J Clin Epidemiol. 2014;67(12):1291-4.

22. Levac D, Colquhoun H, O'Brien KK. Scoping studies: advancing the methodology. Implement Sci. 2010;5:69.

23. Tricco AC, Lillie E, Zarin $\mathrm{W}$, O'Brien $\mathrm{K}$, Colquhoun H, Kastner M, et al. A scoping review on the conduct and reporting of scoping reviews. BMC Med Res Methodol. 2016;16:15.

24. Preferred Reporting Items for Systematic Reviews and Meta-Analysis extension for Scoping Reviews (PRIMSA-ScR). 2015. Available from: http://www.prisma-statement.org/Extensions/InDevelopment.aspx Accessed 18 October 2017.

25. Monteiro CA, Cannon G, Moubarac JC, Levy RB, Louzada MLC, Jaime PC. The UN Decade of Nutrition, the NOVA food classification and the trouble with ultra-processing. Public Health Nutri. 2018;21(1):5-17.

26. United Nations. Sustainable Development Knowledge Platform; 2018. Small Island Developing States. Available from: https://sustainabledevelopment. un.org/topics/sids/list Accessed 15 October 2017.

27. Mourad O, Hossam H, Zbys F, Ahmed E. Rayyan - a web and mobile app for systematic reviews. Syst Rev. 2016;5:210.

28. Ingram J. A food systems approach to researching food security and its interactions with global environmental change. Food Secur. 2011;3(4):417-31.

29. Food and Agricultural Organization. Natural resources management and the environment in small island developing states. Rome: FAO; 2014. Available from: http:// www.fao.org/3/a-i3928e.pdf Accessed 15 October 2017.

30. Girard AW, Self JL, McAuliffe C, Olude O. The effects of household food production strategies on the health and nutrition outcomes of women and young children: a systematic review. Paediatr Perinat Epidemiol. 2012;26(s1):205-22.

31. Burns C, Kristjansson B, Harris G, Armstrong R, Cummins S, Black A, et al. Community level interventions to improve food security in developed countries. Cochrane Database of Systematic Reviews. 2010. Available from: http:/ / www. cochrane.org/CD008913/PUBHLTH_ community-level-interventions-to-improve-food-security-in-developed-countries Accessed 18 January 2017.

32. Prestwich A, Webb TL, Conner M. Using theory to develop and test interventions to promote changes in health behaviour: evidence, issues, and recommendations. Curr Opin Psychol. 2015;5:1-5.

Manuscript received on 9 April 2018. Accepted for publication on 1 November 2018. 
Objetivo. Explorar las iniciativas de producción de alimentos basadas en la comunidad (CFPI, por sus siglas en inglés) en los pequeños Estados insulares en desarrollo, en particular su impacto sanitario, social, económico y ambiental.

\section{Impacto en la salud y otros ámbitos de la producción comunitaria de alimentos en los pequeños Estados insu- lares en desarrollo: una revisión sistemática exploratoria}

Palabras clave Seguridad alimentaria y nutricional; producción de alimentos; cultivos agrícolas; crianza de animales domésticos; industria pesquera; enfermedades no transmisibles; medio ambiente y salud pública; Islas del Pacífico; Región del Caribe. impacto na saúde, social, econômico e ambiental.

\section{Impacto na saúde e outras áreas da produção alimentar comunitária em pequenos Estados insulares em desen- volvimento: uma revisão sistemática exploratória}

Palavras-chave
Métodos. Uma revisão sistemática exploratória foi realizada utilizando 14 bases de dados eletrônicas para identificar artigos publicados entre 1997 e 2016 sobre CFPI em pequenos Estados insulares em desenvolvimento. Dos 8215 artigos encontrados, 153 foram elegíveis e resumidos. A análise centrou-se na localização geográfica, no tipo de iniciativa, na metodologia, no desenho do estudo, no referencial teórico e no impacto. Resultados. A maior parte da pesquisa foi realizada no Pacífico ou no Caribe (49\% e $43 \%$ dos estudos, respectivamente) e se concentrou principalmente na pesca e na agricultura $(40 \%, 34 \%)$. Os resultados indicam uma predominância de pesquisas focadas no impacto ambiental dos recursos marinhos e costeiros na CFPI, e evidências muito limitadas do impacto das CFPI na saúde humana, particularmente nos resultados relacionados à nutrição e dieta. Não existem quadros teóricos explícitos para explicar o impacto das CFPI.

Conclusões. A evidência do impacto das CPFI em pequenos Estados insulares em desenvolvimento é limitada e as abordagens adotadas são inconsistentes. Esta revisão demonstra a necessidade de estudos e fornece uma base para o desenvolvimento de métodos coerentes para examinar o impacto das CFPI e fornecer evidências para orientar políticas, especialmente aquelas relacionadas à saúde.

Segurança alimentar e nutricional; produção de alimentos; cultivos agrícolas; criação de animais domésticos; indústria pesqueira; doenças não transmissíveis; meio ambiente e saúde pública; Ilhas do Pacífico; Região do Caribe. 